\title{
Teaching dental ergonomics to undergraduate dental students. Why and how? The experience of the Faculty of Dental Medicine of Sofia, Bulgaria
}

\author{
Lydia G. Katrova \\ Department of Dental Public Health, Faculty of Dental Medicine, University of Sofia, 1431 Sofia, Bulgaria.
}

Correspondence to: Prof. Lydia G. Katrova, Department of Dental Public Health, Faculty of Dental Medicine, University of Sofia, 1 Georgi Sofijski str., 1431 Sofia, Bulgaria. E-mail: lydiakatrova@gmail.com

How to cite this article: Katrova LG. Teaching dental ergonomics to undergraduate dental students. Why and how? The experience of the Faculty of Dental Medicine of Sofia, Bulgaria. Stomatological Dis Sci 2017;1:69-75.

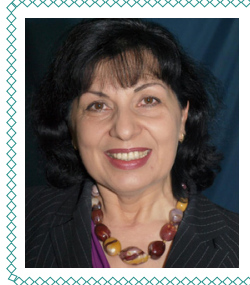

Article history:

Received: 19-03-2017

Accepted: 02-06-2017

Published: 29-06-2017

Key words:

Healthcare reform, dental education reforms, dental ergonomics, teaching dental ergonomics

Prof. Lydia G. Katrova joined the Faculty of Dental Medicine as a lecturer in 1988. She received her Master of Dental Medicine (1981) and Master of Public Health (1990) from the Medical University of Sofia and her PhD degree from the University of Sofia "Saint Kliment Ohridski" in 1997. Her primary research interest is focused on the sociology of the medical professions. She published more than 70 articles in national and international journals, 8 textbooks, 2 monographs and a number of chapters in co-authorship in Bulgarian, English and French on medical ethics, public health, social medicine, dental ergonomics, dental education, leadership and professionalization.

\section{ABSTRACT}

Aim: This article aims to present the development of the concept, the design, and the implementation of the teaching of dental ergonomics in the program for undergraduate dental students within the process of reforming the dental curriculum at the Faculty of Dental Medicine of Sofia, Bulgaria. Methods: A documentary analysis covering the process of implementation and teaching of dental ergonomics to dental students, as a unique teaching module within the Department of Public Dental Health, was completed. The data analyzed was grouped as follows: (1) an overview of the new dental curriculum, organized to answer the European mobility context; (2) the development of the concept and introduction of the disciplines in the program of dental public health; (3) a module of dental ergonomics; and (4) the prospective fields of progress and improvement of teaching of dental ergonomics to undergraduate dental students. Results: The module of dental ergonomics was introduced into the program of public dental health as part of the reformed dental curriculum to conform with the EU membership of Bulgaria (20062007). It comprises 4-5 major topics relevant to the dental practice and the dental profession. The teaching methods are still under development as lecturing is done outside the clinical settings and demonstrations are offered by trained volunteer students in clinical settings. Conclusion: The teaching of dental ergonomics at the Sofia dental school is still under development. The need for integration of dental ergonomics into the dental curriculum was identified by teachers and students. The position of the school board is important to facilitate the efficient cooperation between clinical and public health departments and to connect preclinical and clinical courses in the dental curriculum. License (https://creativecommons.org/licenses/by/4.0/), which permits unrestricted use, distribution, and reproduction in any medium, as long as the original author is credited and the new creations are licensed under the identical terms.
}

For reprints contact: service@oaepublish.com

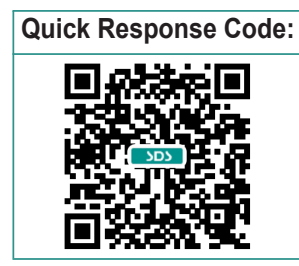




\section{INTRODUCTION}

As long as the techniques applied in dentistry develop, the literature provides more evidence on work-related musculoskeletal disorders faced by the dentist. ${ }^{[1-3]}$ Two out of every three dentists have musculoskeletal complaints or disorders, which vary in severity and time of onset. The most frequent injuries occur in the spine (neck and back), shoulders, elbows, and hands. It has been established that the new technologies do not prevent dentists from these harms. The risk of partial or complete disability is considerable. These injuries can lead to lower productivity and early retirement. There is evidence that a poor working area design and space organization affects the perception of quality of performance by the patients and the job satisfaction of the dentists. ${ }^{[4-7]}$

In addition, alarming data has been published on the occurrence of musculoskeletal discomfort experienced by students. Specific procedures performed with poor posture place the dentist at an increased risk for finger and hand injuries, as well as other injuries which start early during their undergraduate training. The percentage of students experiencing discomfort, measured from the first to the third year, increased to about $70 \%$. The duration and the frequency of the pain also increased. ${ }^{[8-12]}$ An increasing number of women have entered the dental profession in most countries, and it has been confirmed that women are more prone to develop a variety of types of chronic musculoskeletal pain. ${ }^{[13]}$

On the other hand, in the fast developing market of dental equipment, new technologies in dentistry, and dental practice management are proposing an adequate answer to this challenge. Sitting properly in a dental stool, using magnification for visualization, and selecting ergonomically friendly equipment, have proven to be beneficial for the health of the dental clinician. ${ }^{[14-18]}$ The dental associations and the dental industry supported investigations have aimed to improve the dental practice working conditions and work efficiency. ${ }^{[1,9,19,20]}$

Dental schools are considering the growing options to replace their dental equipment with advanced technology. Dental schools have shown a growing awareness of the need for providing students with adequate teaching and training in ergonomics. This ergonomic training is to achieve and keep an appropriate working posture and produce efficient organization of the workplace during the working process. ${ }^{[6,9,21]}$ As a result, many dental schools have adopted specific training in dental ergonomics. ${ }^{[7,8,21,22]}$

In the dental school of Sofia, along with the introduction of the ergonomic module in the program of dental public health, a number of studies were carried out by the students' research group of dental ergonomics. ${ }^{[23-27]}$ Our task was to generate changes in the level of knowledge, awareness, and skills so that students can overcome the most common mistakes in the work setting. ${ }^{[12,22]}$

\section{METHODS}

This article aims to present the development of the concept, the design, and the implementation of a module of dental ergonomics into the program for undergraduate dental students at the Faculty of Dental Medicine (FDM) of Sofia, Bulgaria. To achieve this aim, the following tasks were formulated: (1) overview of the competency-based dental curriculum in the context of the European membership, and the introduction of the discipline into the program of dental public health; (2) development of the concept of dental ergonomics for undergraduate dental students; (3) essential topics and teaching materials into the course of dental ergonomics; and (4) research on the progress and the improvement of teaching the dental ergonomics course.

A documentary analysis is used to cover the process of the implementation and the teaching of dental ergonomics to dental students as a unique module among the disciplines being taught by the department of public dental health.

\section{RESULTS}

\section{Competency-based harmonized dental curriculum and the program of dental public health at FDM}

The module of dental ergonomics was introduced into the program of public dental health as part of the reformed dental curriculum in the context of the EU membership of Bulgaria (2006-2007). A revised dental curriculum was adopted at the Faculty of Dental Medicine in Sofia. The programs of social medicine and dental public health were reshaped in by the recommendations for harmonization of dental education which follows the Bologna declaration statement. ${ }^{[25]}$ This harmonization has occurred over the last ten years (2006-2016) in the dental education curriculum at the FDM of Sofia. The curriculum was improved primarily through covering a larger range of knowledge relevant to the successful professional career. ${ }^{[26,27]}$

In regard to the growth and improvement of the program of dental public health, the material was restructured into a "modular form", and was redistributed into 2 
courses: "social medicine and medical ethics" for the 2nd semester of the 2nd year, and "public dental health" for the 1st and 2nd semesters of the 3rd year dental students. The total duration is $105+45 \mathrm{~h}$ over 3 semesters. According to the program of dental public health, the dental ergonomic matters were structured as elements of the professionalization of dentists and were included in the 2 nd semester of the $3 r d$ year. ${ }^{[27]}$

\section{Conceptualization for the teaching of dental ergonomics to undergraduate dental students}

The purpose of introducing ergonomics into the dental curriculum was to train dental students to maintain health and safety in the workplace while maintaining efficiency in their job performance. The implementation of ergonomic training was expected to become a long-term innovative approach in dental education. Preserving the harmony between the anthropometric parameters of the professional, the equipment design, and the arrangement of the operative field, is considered an important factor for the prevention of musculoskeletal disorders and other chronic occupational trauma. Application of ergonomic principles in a dental practice is also expected to improve the quality of work and increase the productivity of the dental team. This can also improve the overall level of satisfaction of work. ${ }^{[4,7,8,16]}$

The material includes an introduction which comprises the principles of ergonomics, the purpose and subject of ergonomics as a science, its methods of research, and the applied branches which include dental ergonomics and management of the workplace [Table 1]. The teaching of practical knowledge and skills adheres to the logic of the following principles: (1) "entering" the working station - describing the dental clinic and the dental operatory architecture with respect to the necessary motions and activities; (2) rationale of space, time and teamwork - describing the anthropometric characteristics, motion efficiency, access to tools and instruments, complementarities of team roles, and infection control; and (3) operator and environmental harmony establishment - describing the working posture and "stress free" work principles.

The above approaches were proposed to facilitate the integration of the different types of knowledge and their appropriate application in the students' practical assignment performance. ${ }^{[21,22,24,27]}$

The objectives of the teaching in ergonomics were formulated as follows: (1) raising the awareness of the need for knowledge and the practice of ergonomics in dentistry, as a tool to achieve productivity and improve the quality of life; (2) improving attitudes for identification
Table 1: Content of the module and the relevant textbook material on "dental ergonomics"

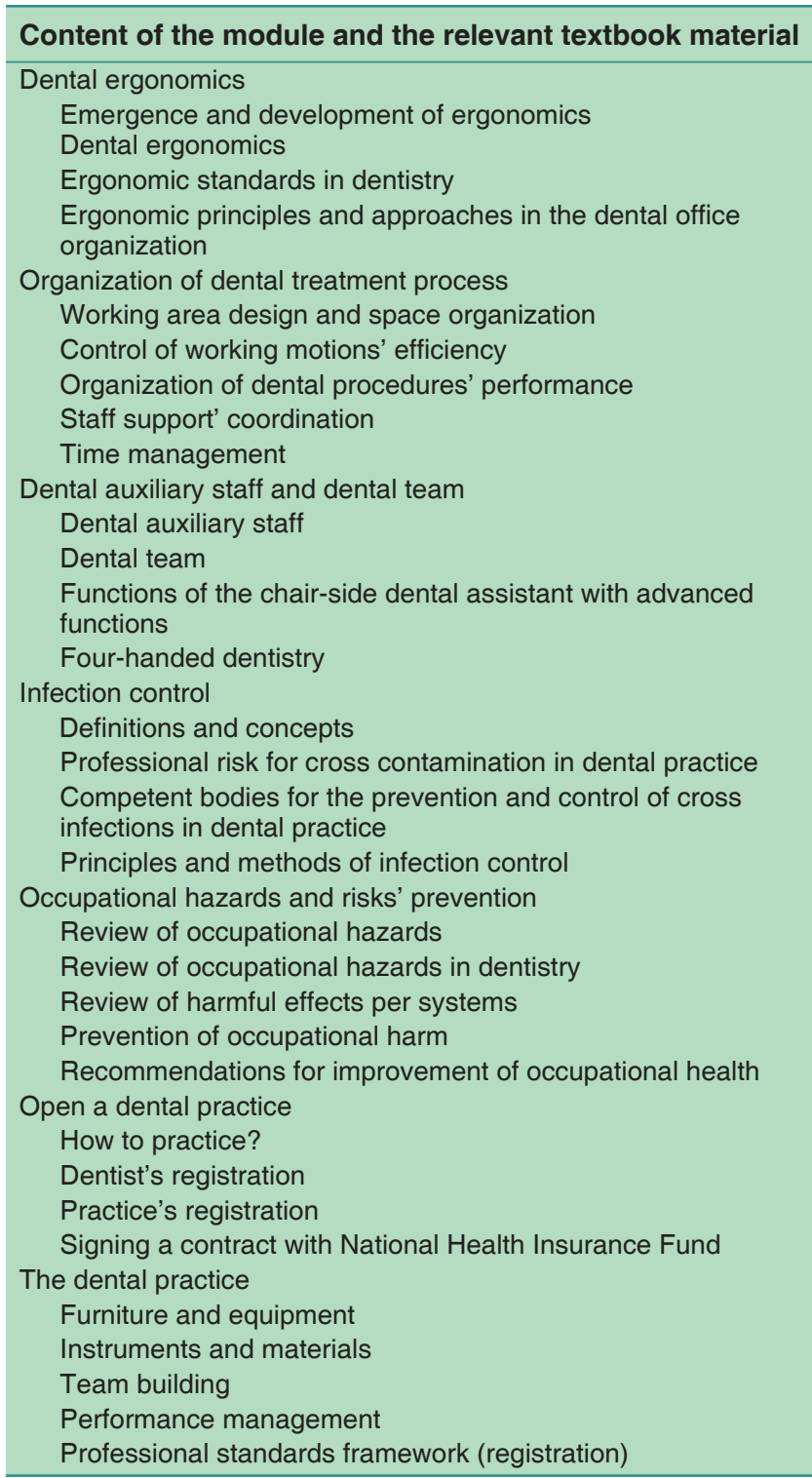

and the avoiding of risk factors in the dental practice through self-assessment of the working posture and a critical view on the overall organization of the working process; (3) implementing (at the faculty level) a positive interest in establishing an ergonomically friendly learning clinical setting; and (4) the design of an educational module of dental ergonomics giving sound essential knowledge and tools for efficient and injury free work.

\section{Essential topics and teaching materials included in the module of dental ergonomics}

The content of the module of ergonomics was organized to strengthen a link to the rest of the dental curriculum, and to establish a sound knowledge base for the entire process of professionalization of the 
dental graduates. Based on the shared experience of our esteemed colleagues, published investigations, programs, and respecting the framework of the subjectoriented curriculum at the FDM of Sofia, the topics, and textbooks which include ergonomic matters were adopted. ${ }^{[7,8,11,12,17,21,24]}$ Ergonomic topics were included in the program of "dental public health" during the 2 nd part of the 2 nd semester of the 3 rd year are presented in Table 1.

In the introduction to ergonomics, the dental students are made aware of the need for knowing and observing the laws of physics, referring to the work and energy required. The following paragraphs give an indication how we approach ergonomic principles in order to involve students and to assist them to understand the importance and objectivity of the issues.

\section{Velocity and distance impacting the time of task performance("at our fingertips")}

As the value of displacement is equal to the time multiplied by the velocity $d=V^{*} t$, the time required for the relocation of an object is a function of velocity $(\mathrm{V})$ and the distance (d). Therefore, the amount of time taken for the performance of an operation (t) can be reduced in two ways: (1) by increasing the speed of displacement of the object (tool, instrument); or (2) by limiting (optimizing) the distance between the hand and the object, and between the hand and the destination point of displacement. It is known that different people perform at different speeds, but the variation is relatively small. The only way to significantly reduce the time of performing a given operation is to optimize the distance between the operator and the necessary tools. This facilitates the access of the object to be transported and reducing the distance to the destination point. Therefore, we should be aware that "saving time", when performing a work task, results from the organization of the workplace per accordance with anthropometric indicators. All the tools and devices must be located "at our fingertips".

\section{Weight and motion (gravity should "work for the operator")}

In the process of performing a particular task, some amount of kinetic energy $\left(E_{k}\right)$ will be exerted. The amount of work $(W)$ is equal to the energy applied $\left(E_{k}\right)$ to overcome the forces generated by the weight of the object moved and the maintenance of the posture of the operator (overcoming the forces generated by the operator's body or his/her extremities' weight). In turn, the perceived weight is a function of the mass of the object, the specific weight of the material, and the gravity constant. Like energy, mechanical work is a scalar variable. According to the work-energy theorem, if an external force acts on a rigid object causing its kinetic energy to change from $E_{k 1}$ to $E_{k 2}$, then the mechanical work $(\mathrm{W})$ is given by the following equation: $\mathrm{W}=\Delta \mathrm{E}_{\mathrm{k}}$ $=E_{k 2}-E_{k 1}=0.5^{*} m^{*}\left(V_{2}^{2}-V_{1}^{2}\right)$, where $m$ is the mass of the item and $v$ is the velocity of the item acquired when moved by the operator. Gravity is constant. Therefore, energy savings can be obtained at the expense of reducing the mass of the item (tool, instrument) and the appropriate choice of the item's material (specific weight). The mass/size of the item (tool, instrument) may not be reduced impractically. This reduction in size would lead to difficult handling characteristics and the inability to sterilize the item. Hand pieces and hand instruments must be as light as possible, but also be an "anthropometric replica" of the operator's hand. The instruments should be arranged in a logical sequence by order of their use. The operator has to keep a stable position on the horizontal (keeping the neutral working posture) and eliminate repetitive movements while "looking for" the appropriate tool. The assistant has to "drop" the instrument being positioned higher than the operator's hand. Saving energy when performing a task will depend on the proper choice of the shape and material of the instruments, and their optimal arrangement in the horizontal and vertical planes.

\section{Vector of power (posture and motion)}

The power $(\mathrm{F})$ applied during the time of the operation is a vector variable, characterized by the size and direction of the force. $\mathrm{F}=\mathrm{d}(\mathrm{mv}) / \mathrm{dt}, \mathrm{W}=\mathrm{F}^{*} \mathrm{~d}=\mathrm{F}^{*} \mathrm{~d}^{*} \cos \Phi$, where $\Phi$ is relevant to the angle between the force vector and the displacement vector. The simplest case is the force applied is perpendicular to the direction of the motion, making the integrand zero.

Therefore, to use less energy when performing a particular task, the hand that holds the object must be in a position close to perpendicular towards the horizontal plane (floor of the room, the Earth's surface). The closer to the body the arms are placed during work; the less energy is exerted.

The "economic" working position of the body is the upright, symmetrical posture. ${ }^{[24]}$

\section{Working positions, access to tools and the working field of the dentist}

1. The starting position for most treatment is at approximately 11-12 o'clock.

2. During most of the procedure, the dentist works seated behind the patient (11-12 o'clock).

3. In the treatment of the lower right or the upper left teeth, the dental practitioner works in the standing 
position in front of the patient (8.30-10.00 o'clock).

4. Robust active stand combines with dynamic working methods: the alternation of work and traffic-alternating sitting and standing position.

5. When working on a seated patient with an upright body, it is better to ask the patient to rotate their head in order to obtain direct visibility into the patient's mouth. ${ }^{[28]}$

\section{Working posture for the dental assistant, teamwork}

The best sitting position for the dental assistant is sitting upright with the back straight and weight evenly distributed over the seat. Legs should be slightly separated with the feet flat on the ring around the base of the chair. Thighs should be parallel to the floor, and the front edge of the chair is even with the patient's mouth. Position the chair close to the side of the patient with the knees facing toward the patient's head. The height of the chair should be such that the assistant's eye level is positioned at 4 to 6 inches (10$15 \mathrm{~cm}$ ) above the operator. ${ }^{[29]}$

\section{Research of progress and improvement of teaching of the dental ergonomics module}

The following goals for positive development in achieving correct working posture and an ergonomic workplace arrangement were formulated: (1) a competitive work environment and a vision for the dental practice; (2) patient safety and comfort; and (3) a team working efficiency and safely.

Observation through visualization of the working posture, surveys on the preparedness and motivation of dental students and teachers to work ergonomically, training involving different departments performed by volunteer students, were applied over a period of three years. Surveys were carried out before and after the implementation of correct posture demonstrations in the clinical environment by volunteers. ${ }^{[5,27]}$

By using self-directed questionnaires (distributed to 260 students from a total of 685 and their teachers with 130 responses), the need for ergonomic training was studied. The protocol includes pictures of the leg and arm positions, and the symmetry of the spine and neck position. The documented working posture of students demonstrated that most of the students $(66.67 \%$ of male and $57.14 \%$ of female) do not sit properly, or work primarily in the standing position. The most frequent mistakes, when working in sitting position, consisted of severe torsion of the spine (76\%), bending of the neck $(47 \%)$, and inappropriate clock-face position (63\%). Unexpectedly, it was noted that the 5th year students were making more mistakes than the 4 th year students
( $73 \%$ of the 5 th year vs. $62 \%$ of the 4 th year). No significant difference by gender was detected. ${ }^{[12]}$

Based on the results from the studies, valuable facts had been detected about the teachers' and the students' perceptions, attitudes, and expectations. It was shown that training should include an improved direct communication between the professors and the students, and efforts have to be made to enhance the preparedness of student. The focus of interest for the students and teachers was directed toward the earlier discussion of the working posture, as it takes time to incorporate proper working habits. As shown by the answers of $78.6 \%$ of teachers, they expect that the demonstration sessions anticipate the clinical training. Almost all of the students $(90.2 \%)$ and more than half of the teachers $(61.1 \%)$ consider that ergonomic training is necessary and should be initiated at the stage of the mannequin course. Both students and teachers understand the need for ergonomic training and appreciate the improvement of the clinical settings dictated by the ergonomic principles. Students and teachers believe that the integration of ergonomics into the dental clinical training is possible and necessary. ${ }^{[5]}$

\section{Visualization of the need for ergonomic training}

Pictures taken before and after the training demonstrated the extent of the improvement. Review of the pictures showed that the knowledge is not always applied in practice. About $15 \%$ of students work in a standing position. Less than $45 \%$ of the students work from behind the patient. Demonstration of the appropriate working posture is the preferred method of introducing ergonomics into the clinical dental education $(43.1 \%$ of students and $78.6 \%$ of teachers). ${ }^{[12]}$

\section{Demonstrations and practical training}

Explanations about the potential harm of an incorrect working posture, as an occupational risk, are given in the "dental practice management" module lectures. ${ }^{[24]}$

\section{DISCUSSION}

There are several publications discussing the need for an ergonomically organized working environment, especially in the latter decades of the 20th century. The scientific investigations proposed the development of normative guidelines for the occupational safety and the improvement of work efficiency. Eminent investigators have published dental ergonomic recommendations on the internet as well. ${ }^{[28,29]}$ Multiple research papers have shown that the lack of respect for ergonomics in a dental practice ends in the loss of efficiency and increases professional harm to the dentists' health. The ergonomically friendly working environment is a 
requirement for efficiency and safety. ${ }^{[14,18,20]}$

Dental practitioners and dental ergonomic specialists agree that it is necessary to train people to achieve a proper working posture and develop healthy stereotypes. In many countries of the EU and North America, the course of "dental ergonomics" is taught by the clinical departments, or through specific training which introduces students to the dental equipment and the working environment. ${ }^{[21]}$ Therefore, models of open infrastructures and flexible collaboration, rather than differentiation of rigid departmental organization, has become common and beneficial to the introduction of a course in dental ergonomics. ${ }^{[9,10,16]}$

The Department of Public Dental Health of the Medical University of Sofia, Faculty of Dental Medicine, founded in 1991, in many aspects is a pioneer in dental education. The elaboration of an academic program and its integration into the accredited undergraduate dental curriculum was the reason, and predisposing condition, for the development of a particular module of dental ergonomics. ${ }^{[27]}$ The flexibility and cooperation in upgrading the program of "public dental health" were of paramount importance for maintaining dynamics within the subject-oriented dental curriculum. Led by this idea, and assisted by our esteemed colleagues from the dental schools of Europe, the USA, and especially from the European Society of Dental Ergonomics, we structured a comprehensive module of ergonomics for dental professionals. These modules are open for update and are fitting with the new learning environment and new learning technologies. ${ }^{[5,21,23]}$

This ergonomic training plans to include both students and teachers to start as early as possible, i.e. during the pre-clinical mannequin courses. ${ }^{[22,24,27]}$ As the preclinical and clinical training are more or less separate, the introduction of ergonomics during mannequin courses would be a bridge to link instrumental control with the skills of treating patients.

In conclusion, the answer to the question "why include dental ergonomics into the undergraduate curriculum" is consistently positive. The question "how to achieve full integration of ergonomic training into the process of professionalization" is still pending. The inclusion of modules of ergonomics into the dental curriculum may take on different forms, time of inclusion, and volume of the training. However, it needs special attention and comprehensive efforts of clinical, technical, and administrative staff. Therefore, the position of the school, especially within a subject-oriented curriculum, is imperative to facilitate the efficient cooperation between students, educators, and departmental staff. This incorporation has many components - humanistic, logistic, and marketing. Conceptual, contextual, and performance improvement of ergonomic courses and their close integration within the theoretical and practical clinical training represent an important task to fulfill.

\section{Authors' contributions}

L.G. Katrova contributed solely to this article.

\section{Acknowledgments}

I thank Dr. Jon Wagner for his contribution in language editing.

\section{Financial support and sponsorship}

None.

\section{Conflicts of interest}

There are no conflicts of interest.

\section{Patient consent}

Not applicable.

\section{Ethics approval}

Not applicable.

\section{REFERENCES}

1. Belenky M, Rucker LM. The infinity of opportunity: breaking barriers to technological change in dentistry. J Am Coll Dent 2000;67:23-5.

2. Rucker LM. Ergonomic risks and clinical dentistry: a profession of pain. Dr Dent Mag 2003;4:32.

3. Valachi B, Valachi K. Mechanisms leading to musculoskeletal disorders in dentistry. $J$ Am Dent Assoc 2003;134:1344-50.

4. Chaffin DB, Andersson G, Martin BJ. Occupational Biomechanics. 3rd ed. New York, NY: Wiley Inter Science; 1999. p. 355-91.

5. Katrova L, Tsvetanov K, Ivanov I. Perceptions of students and practitioners of dental ergonomy as a tool of internal marketing. Poster of Annual Meeting of the ESDE; 2013 May 17-18; Sofia, Bulgaria.

6. Rucker LM. Ergonomic risks and clinical dentistry: neutralizing the risk factors. Dr Dent Mag 2003;5:38.

7. Belenky MM. Human performance in dental education: the Maryland model. New directions in psychomotor education at the Baltimore College of Dental Surgery, Dental School, University of Maryland at Baltimore. J Jpn Assoc Dent Sci 1994;7:34-53.

8. Boyd MA. Human performance in dentistry. The application of performance logic in dental education and practice. The performance simulation laboratory. Vancouver, BC Canada: The University of British Columbia; 1994.

9. DePaola DP, Slavkin HC. Reforming dental health professions education: a white paper. J Dent Educ 2004;68:1139-50.

10. Rising DW, Bennett BC, Hursh K, Plesh O. Reports of body pain in a dental student population. $J$ Am Dent Assoc 2005;136:81-6.

11. Garcia P, Gottardello A, Wajngarten D, Presoto C, Campos J. Ergonomics in dentistry: experiences of the practice by dental students. Eur J Dent Educ 2016; doi: 10.1111/eje.12197

12. Katrova L, Ivanov I, Ivanov M, Pejcheva K. "Ergonomization" of the working environment and building up of healthy working posture of dental students. J IMAB 2012;18:243-50. 
13. White SW. Ergonomics how does dentistry fit you? Women's Dent $J$ 2003;1:58-62.

14. Boyd MA, Rucker LM. Effects of immediate introduction of indirect vision on performance and posture. J Dent Educ 1987;51:98-101.

15. Brookhuis K, Hedge A, Hendrick H, Salas E, Stanton N. Handbook of Human Factors and Ergonomics Models. Florida: CRC; 2005.

16. Harrison DD, Harrison SO, Croft AC, Harrison DE, Troyanovich SJ. Sitting biomechanics part 1: review of the literature. J Manipulative Physiol Ther 1999;22:594-609.

17. Improving Dental Ergonomics. UBC Reports, April 6, 2011. Available from: www.publicaffairs.ubc.ca/2011/04/06/improvingdental-ergonomics. [Last accessed on 2017 Jun 14]

18. Valachi B, Valachi K. Preventing musculoskeletal disorders in clinical dentistry. J Am Dent Assoc 2003;134:1604-12.

19. Rucker LM. High-risk and low-risk ergonomics: do you work for your equipment or does your equipment work for you? Dr Dent Mag 2002;3:24.

20. Rucker LM, Boyd MA. Optimizing Dental Operatory Working Environments. In: Murphy DC, editor. Ergonomics and the Dental Care Worker. American Public Health Association; 1998. p. 301-18.

21. Hokwerda O, de Ruijter R, Shaw S. Adopting a healthy sitting working posture during patient treatment. J Calif Dent Assoc 2002;30:139-48.

22. Katrova L, Ivanov I, Ivanov M, Shoaib M, Miloshev K, Tsvetanov
K. Dental ergonomics' teaching methods and good practices in the Faculty of Dental Medicine, Sofia. Poster of Annual Meeting of the ESDE; 2013 May 17-18; Sofia, Bulgaria.

23. Rucker LM. Performance simulation: the method. $J$ Res Educ 1987;4:276-350.

24. Katrova L. Basics of dental health and dental practice management. In: Katrova L, editor. Leading Technologies in Dentistry. 2015.

25. Cowpe J, Plasschaert A, Harzer W, Vinkka-Puhakka H, Walmsley AD. Profile and competences for the graduating European dentist update 2009. Eur J Dent Educ 2010;(14):193-202.

26. Eaten K, Widstrom E, Katrova L. Education in and the practice of dental public health in Bulgaria, Finland, and the United Kingdom. Oral Health Dent Manag 2009;8:30-8.

27. Katrova L. Developing a program of "public dental health" within a subject oriented undergraduate dental curriculum. EC Dent Sci 2017;8:67-78.

28. Rucker LM, Sunell S. "Dental Clinical Ergonomics Module" materials, 22 modules. Available from: https://secure.dentistry.ubc. ca/survey/, 2006-date. [Last accessed on 2017 Jun 14]

29. Rucker LM. Transfer of web-based ergonomics health promotion knowledge into the clinical workplace. Newsletter of the BC-Yukon Region of the Association of Canadian Ergonomists; 2004. p. 1-2. 